It is unfortunate that there is no indication of a sugar indigestion, such as is given for fat and casein by the fat and casein curds.

In conclusion I wish to emphasize the importance of discriminating between the fat and casein curds and of making use of this knowledge in the feeding of dyspeptic infants.

BIBLIOGHAPHY.

Knopfelmacher: 71 Versamml. der Gesell. Deut. Naturf. und Aorzte September, 1809; Jahr, für Kinderheilkunde, 51, 1000; Ibid. 52,1900 .

Selter: 78 Versamml. der Gesell. Deut. Naturf. und Aerzte, Stuttgart, 1006, p. 177 .

'Talbot: Boston MEd. and Sura. Jour., June 11, 190s, p. 905; Jan. 7, 1800, D. 13

Southworth and Schloss: Arch. Pediat., April, 1000.

Widerhofer: Gerhardts Hundbuch der Kinderkrankheiten, iv, 2

Uffelman: Deut. Arch. für Klin. Med., xxviii, 1880. Ibid, 1881.

Uffelman: Arch. für Kinderheilkunde, ii, 1881

Bluuberg: Experimentelle und Kritische Studien uber Siluglingfeces, elc., Berlin 1897.

Biedert: Kinderernahrung im Slugglingsulter, etc., 1005, tifth elition.

Wegschneider: Ueber die normale Verdauung bei säuglingen. Inuup. Dissert., Strassburg, 1875.

Schmidt and Strassburger: Die Feces des Menschen.

Herter and Kendall: Jour. Biol. Chem., v, February, $15(19$.

Herter and Kendall: Ibid. Oetober, 1908.

Fendnll: Ibid., vi, November, 1006; June, 1909.

\section{UNSUSPECTED DIABETES, A CAUSE OF RAPIDLY FATAL COMA.*}

nY W, W. MINkH, M.D.,

Medical Eixaminer of Ware, Mass.

I was called, as family physician, to the following described case of coma occurring in a woman who was thought to be free from any disease, but which unconscious condition rapidly terminated in death.

K. H., aged forty-one, unmarried, usually cmployed in domestic service, five feet and eight inches in height and weighing about two hundred and forty pounds. While engaged in washing of laundry clothes at her sister's home, suddenly complained of not feeling well, stopped her work at the washtub, went upstairs to her room and in a few minutes fell into an unconscious condition. This began at about nine o'clock in the forenoon and continued till her death, which occurred about noon, the coma having lasted three and one-half hours. The cause of this fatal attack of coma did not appear evident to me before her death.

She was thought to be in a good condition of health and free from disease. About three months before her death she had given up her position as a domestic in a family where she had served for five years, returning to her sister's home to have a rest, as she was tired of her work. About two months before her death she was in bed for one and one-half days with a tired feeling, had a flushed face, but had no physician and was soon well again. She wanted her sister to get through with her washing early, so took hold of the washing work to help her. When at the tub she suddenly stooped over and said, "Oh, my head, my head." She soon vomited some ham and sliced beets which had been eaten for her breakfast. The pain was in the back part of her head near her neck. She had slight assistance in going upstairs to her room. She talked for a few minutes, saying that she was very sick, but had no pain except in the back part of her neck. Then she fell into an unconscious state, and on my arrival could not swallow.

There was no paralysis or stertorous breathing, her pulse not rapid, respiration comparatively free, no twitching, spasmodic movement or convulsive attacks.

* Read before the Massachusetts Medico-Legal Society.
There was no edematous condition of her limbs or face. Her complexion was natural, her eyes showed no abnormal action of muscles and the pupils were equal and of medium size; her tongue appeared to fill her mouth, and swallowing was not possible. She had no epileptic seizure. Her heart and arteries were considered sound. Her appetite had been very good but was not considered abnormal. There was no inordinate desire for water or fluids. She did not have to rise at night to evacuate her bladder. Her urine was not known to be abnormal in quantity. Her bowels were regular. She had considerable raising of gas from her stomach, but did not, have nausea. She was not subject to attacks of faintness, pain about her heart or to hard headaches or disturbed vision, except slight want of elearness of sight, but could sew and read well. Her relatives considered her to be free from any discase. Soon after her death I obtained, by use of a catheter, a few ounces of her urine. This was of ordinary color and fairly clear. On using Fehling's test for glucose, I found a heavy precipitate of ycllow suboxide of copper, which appeared promptly on boiling and apparently was without in precipitate of albumen. I thercfore came to the opinion that her death probably was from diabetic coma and gave a certificate to that effect. She was seen by another physician of experience, whose opinion of the cause of her death coincided with mine.

Osler states that "diabetic coma, first studied by Küssmaul, is the most serious complication of the disease, and carries off a considerable proportion of all cases, particularly in the young. It may occur when diabetes is unsuspected, as in two cases reported by Francis Minot. lirerichs recognizes three groups of cases: 1 . Those in which after exertion the patients were suddenly attacked with weakness, syncope, somnolence, and gradually deepening unconsciousness, death occurring in a few hours. 2. Cases with preliminary gastric disturbance, such as nausea and vomiting; or some local affection, as pharyngitis, phlegmon or a pulmonary complication. In such cases the attack begins with headache, delirium, great distress and dyspnea, affecting both inspiration and respiration, a condition called by Küssmaul air-hunger. Cyanosis may or may not be present. .If it is, the pulse becomes rapid and weak and the patient gradually sinks into coma, the attack lasting from one to five days. There may be a heavy sweetish odor of the breath due to the presence of acetone. 3. Cases in which, without any previous dyspnea or distress, the patient is attacked with headache and a feeling of intoxication and rapidly falls into a deep and fatal coma."

Simon, in the recently issued third edition of his work on "Physiological Chemistry," says: "Within the past ten years it has been found that, in a not inconsiderable number of cases of diabctes, degenerative lesions can be demonstrated in the pancreas, and there can be no doubt at the present time that a certain percentage of cases are directly referable to such origin. That the islands of Langerhans are here primarily concerned has been demonstrated by Opie. In this connection Cohnheim's researches are very significant, in which he could show that while neither pancreas nor muscle-splitting tissue contain ferments which are capable of splitting glucose by 
themselves, extensive glycolysis is effected if an extract of pancreas and muscle plasma, conjointly, are allowed to act upon glucose. A condition thus exists which seems quite analogous to the relation between trypsin and enterokinase.

"In the milder forms of diabetes an insufficiency on the part of the muscle tissue manifestly does not exist, as it is possible to prevent the occurrence of glycosuria, temporarily at least, if the demand for sugar is increased by abundant muscular exercise. That a hepatogenic diabetes may coexist with a myogenic form, however, cannot be doubted."

The use of sodium bicarbonate solutions by rectal injection, by hypodermoclysis, by lavage or half-teaspoonful doses by the mouth has been proven to be very valuable in the so-called uremic attacks if not connected with diabetes, and, in exceptional instances, of diabetic cases.

Progressive Medicine quotes Bosanquet as saying, in his Goulstonian lecture, that there is sufficient evidence available to establish beyond the possibility of doubt the fact that there is some connection between the pancreas and diabetes.

Prof. T. 13. Futcher, of Johns Hopkins University, in his excellent article in the first volume of Osler's " Modern Medicine," gives an interesting and instructive historical account of the contributions which have been made at different times by various skilled laboratory workers to our knowledge of the processes of metabolism and its disturbances in the subjects of diabetes. His article states that "according to Cohnheim's view, the sugar in the blood is burned up in the muscles through the agency of a glycolytic substance which results from the interaction of bodies produced in the pancreas and muscles.

"It is not alone the metabolism of the carbohydrates that is disturbed in diabetes. It is only in the last few years that students of this disease are awakening to the fact that there is also a marked disturbance in fat metabolism. There is now practically conclusive evidence that the power of the tissues to oxidize the fat of the food and body is markedly lowered. In the last five years evidence has gradually accumulated to show that beta-oxybutyric acid and its derivatives, diacetic acid and acetone, arise as the incomplete oxidation of fat. This is the generally accepted view as to their origin at the present time. It will naturally be inferred that in the regulation of the diet of diabetics we must not only consider the carbohydrates, but we must pay more attention to the prescribing of the amount and kind of fat than we have been accustomed to do heretofore.

"Diabetes is sometimes considered among the auto-intoxications. We have no proof that an excess of glucose in the circulating blood is capable in itself of producing any toxic symptoms. Diabetic coma, the most serious complication of the disease, however, is definitely due to an acid auto-intoxication."

"Acetonemia is a toxemia which develops in the terminal stages of diabetes. It is due to an accumulation of acetone in the blood. It is also called diabetic coma. It develops acutely. A sudden onset is attended by sharp pain in the stomach, with nausea and frequently vomiting. At the same time there is severe dyspnea. The breathing is irregular and of a panting character, with inspiratory and expiratory dyspnea. There may or may not be cyanosis. The patient is obliged to sit up in bed on account of the air hunger. Restlessness begins at once; delirium begins within the first hour; in a few hours coma sets in. The temperature is subnormal; the pulse is irregular and soon becomes weak and thready. The odor of acetone is detected in the breath." 1

The occurrence of diabetic or uremic coma without being accompanied by other markedly pronounced symptoms I have found mentioned elsewhere.

"Acetonuria is found in states of inanition and in fevers, especially typhoid fever, pneumonia, scarlet fever, measles, acute rheumatic fever, acute miliary tuberculosis and septicemic conditions, but is much less apt to occur if the dietary allows sugar and starch. It is also found in the cancerous cachexia, especially carcinoma of the stomach; in certain mental and nervous diseases, as in melancholia and locomotor ataxia; in autointoxication of intestinal origin; and after chloroform anesthesia. The acetonuria associated with diabetes is of more clinical importance than in these mentioned. The simultaneous finding of glucose and acetone in the urine is good proof of the existence of diabetes, and the larger the amount of acetone, the more severe is the disease." "2

In Cattell's valuable and useful work on "PostMortem Pathology." recently published in Philadelphia, I find the following excellent summary of present knowledge of the pathological findings in diabetes:

"Diabetes mellitus is a constitutional disease characterized by the continued secretion of large amounts of pale cloudy urine, of high specific gravity, containing glucose and, at times, acetone, diacetic acid and beta-oxybutyric acid. It is, as a rule, associated with excessive hunger and thirst, and sometimes with increase in fat, and at other times with progressive emaciation. It occur's most frequently in adult males, Hebrews being especially predisposed. It is due to some failure properly to utilize certain carbohydrates in metabolism. There is a tendency to destructive changes in the tissues and to death from coma. It may be caused experimentally by ingesting phloridzin and by puncture of floor of fourth ventricle. Glycosuria is seen with exophthalmic goiter, certain neuroses, some diseases of the liver, cirrhosis, lesions of the pancreas, injuries to the nervous system, destruction of gray matter in the floor of the fourth ventricle, extirpation of cervical ganglion, pancreatic affections such as calculi, atrophy, carcinoma, necrosis, fatty degeneration, cysts, acute and rarely chronic interlobular pancreatitis. Some cases of the disease

1 Musser's Physical Diagnosis.

2 Butler's Diagnostics of Internal Medicine. 
show an absolutely healthy pancreas, yet it occurs often with chronic interacinous pancreatitis. Diabetes is closely related to destructive lesions of the islands of Langerhans, especially with hyaline changes and interacinous pancreatitis. In diabetes the number of islands may be diminished and the pancreas be nearly always atrophied. Arterial sclerosis accompanies many cases of diabetes; also, acromegaly may accompany diabetes. It is occasionally associated with tabes. The celiac ganglion is atrophic in this disease. (Orth.) Neuroretinitis is very common and there may be hemorrhages in the retina and opacities in the vitreous. The most usual change is a thickening and congestion of the membrane. The blood generally appears normal, but contains an increased amount of glycogen and may be loaded with finely divided fat which floats on the surface in a cream-like layer. There may be lipemic clots in the vessels. Fat embolism of the pulmonary vessels has been described. The myocardium is pale and soft; rarely it may be hypertrophied. Advanced fatty degeneration of the muscular fibers is the characteristic change in long-standing cases of diabetes. Croupous pneumonia and bronchopneumonia, chronic interstitial pneumonia and tuberculosis are common complications; many of them terminate in gangrene.

"The lung may soften (malacia) and, becoming mixed with stomach secretions post-mortem, form the so-called pneumomalacia acida. It has a sour but not a gangrenous odor. The spleen is usually small, pale and soft, but may be enlarged and congested. Diffuse nephritis with fatty degeneration, and frequently glycogenic degeneration, most marked in the pyramids, may occur. Boils, carbuncles, onychia, eczema and gangrene of the extremities are common. The liver is usually enlarged, often congested, abnormally firm to the touch and gives the glycogen reaction; fatty degeneration is common. Do not mistake diabetes mellitus for alcaptonuria; in the latter disease pigmentation of the cartilages or ochronosis may occur. Some alcaptonuriacs do not show ochronosis, but thus far all the cases of ochronosis exhibit alcaptonuric changes in the urine.

"Established facts concerning diabetes: (1) Considerably more than one half of all cases are due to a destructive disease of the pancreas. (2) When due to disease of the pancreas, injury to the islands is responsible for the disturbance of metabolism in the carbohydrates. (3) Common lesions injuring the islands are chronic interacinous inflammation and hyaline degeneration. (4) Other lesions of the pancreas do not attack the islands of Langerhans, but produce diabetes by destroying the interacinous islands along with the secreting parenchyma. (Opie.) According to the experiments of Sauerback upon guinea-pigs, total extirpation of the pancreas or the tying of its secretory duct gives rise to atrophy of the islands of Langerhans and the subsequent development of diabetes.

"The Bremer-Williamson reaction of diabetic blood may be obtained a considerable time after death; the procedure is as follows: $40 \mathrm{cmm}$. of water are placed in a small narrow test tube; to this are added $20 \mathrm{cmm}$. of blood, $1 \mathrm{cmm}$. of a $1: 6,000$ aqueous solution of methylene blue and $40 \mathrm{cmm}$. of liquor potassæ. The test tube is placed in water for four minutes, at the end of which time, if the blood is diabetic, the blue color will have disappeared and a dirty green color will have taken its place. Williamson obtained the reaction in 43 cases of diabetes tested and thinks it is due to an increase of glucose in the blood. The reaction is of special value in coma where urine cannot be obtained."

\section{Elinital \$Department.}

\section{CASE OF POISONING BY MERCURIC BICHLORIDE.*}

BY J. WINTHROP SPOONER, M.D.,

Medical Examiner of Hingham, Mass.

Mns. D., aged twenty-one, married, mother of two children, had been through a very trying experience with her husband about two years ago. The husband is now an inmate of one of the state insane hospitals, an incurable. She had at the time of her death recovered from the melancholia of two years ago and was as bright and cheerful as could be expected. As her mother stated, she had had sufficient trouble to lead to suicide, but she had lived it down.

she had been subject to headaches for a long time, and when these were very severe had resorted to headache powders for relief.

On the morning of Nov. 9, 1908, she had been preparing her little daughter to make a visit on the child's aunt. She had complained of headache, and finally told her sister, who was with her, that she must take a headache powder or tablet. She went upstairs with this intention, but was gone so long that the sister sent, for her. Mrs. D. came downstairs looking very pale and sick. She said that she had never taken a headache powder which tasted so queerly or made her so sick, and said she must have taken the wrong medicinc. Her aunt, who lived next door, was summoned, and she gave her mustard and water. She vomited very soon. She had previously vomited a watery fluid. A second emetic was given, but produced no emesis. Strong coffec was given, which she was unable to swallow. In the meantime the aunt had called the doctors from Hull, Hingham and Cohasset, but could get none of them. She died a little more than an hour after taking the fatal dose.

Autopsy at 9 A.M., Nov. 11, 1908.

Dr. Gilman Osgood, of Rockland, rendered valuable assistance, and Dr. W. H. Sturgis, of Hull, was also present. The stomach and lower part of the esophagus were placed in clean jars, together with sections of the liver, spleen and one kidney, and submitted to Dr. W. li. Whitney for examination.

In the section of the esophagus were found a number of pieces of a white chalky substance, the largest about a quarter of an inch in diameter, which resembled a broken tablet. There was a marked congestion of the lungs, heart, liver, spleen, kidncys and brain, but no structural change. The uterus was functionating. Dr. Whitncy reported that he found sufficient corrosive sublimate to cause death. "From this it appears that she must have taken a corrosive sublimate tablet instead of a headache powder."

1809. 